\title{
Adolescentes y noticieros de televisión. Televidentes disconformes y opinantes
}

\section{Teenagers and TV News. Critic and Concerned Audiences}

\author{
Loreto Rebolledo \\ Universidad de Chile \\ mareboll@uchile.cl
}

\begin{abstract}
Resumen
Este artículo recoge los resultados de una investigación que, a través de entrevistas en profundidad realizadas a adolescentes hombres y mujeres de la ciudad de Santiago, buscaba establecer el consumo y uso que hacen adolescentes de Santiago de los noticiarios de televisión y determinar sus percepciones respecto a como se los representa en ellos. El artículo profundiza en el contexto cotidiano en el cual se "consumen" los noticiarios así como en el uso social y percepciones de los discursos de información trasmitidos por los noticieros difundidos por la televisión chilena por parte de grupos de adolescentes.
\end{abstract}

Palabras clave: adolescentes, noticiarios, televisión.

\begin{abstract}
This paper offers the results of an investigation about uses and consumption of TV news by teenagers in Santiago, Chile. The study tends to acquire teenagers' perceptions about how media represent them, focusing on deep interviews to male and female youngs and by describing their consumption contexts.
\end{abstract}

Keywords: Teenagers, news, television.

\section{Introducción}

Desde hace varios años la televisión ocupa un lugar muy importante en la vida y cultura cotidiana de las mayorías, por lo que juega un papel estratégico en los modos de construcción de imaginarios e identidades y en los modos de percibir tiempo y espacio (Rincón, 2002). En Chile, la afirmación anterior se constata en la cantidad de televisores por hogar, en el espacio que ocupa en la conversación diaria y en la agenda de los medios 
de comunicación, cuyos titulares de primera plana en muchos casos surgen de la programación o de noticias que se originan en la televisión. De acuerdo a la VI Encuesta del Consejo Nacional de Televisión (CNTV) de 2008 el promedio de televisores por hogar era de 2,4 (3,0 en el grupo ABC1; 2,6 en el C2 y C3; y 2,1 en el D y E) y un $76 \%$ de las personas afirmaba consumir diariamente televisión abierta. De ellos, el consumo diario promedio del grupo de edad de 16 a 25 años era 1 hora 54 minutos, inferior en 32 minutos al resultado de la medición de $2005^{1}$.

Entre los adolescentes y jóvenes uno de los agentes de socialización importantes son los medios de comunicación y dentro de ellos la televisión sigue ocupando un lugar central en el diseño de su agenda de conversación y en su vida cotidiana (Rincón, 2002). Pese a la cada vez mayor gravitación de Internet la televisión sigue siendo uno de los principales símbolos de identificación e información para los adolescentes, ya sea por las horas con la pantalla encendida -cuentan con un promedio de seis horas diarias de tiempo libre, un tercio de las cuales ven televisión ${ }^{2}$ - o por los temas que señalan como motivo de preocupación.

La televisión ocupa los lugares vacíos dejados por otros agentes de socialización en tiempos libres luego del colegio, antes de que los padres regresen del trabajo y cuando los amigos no están presentes. Por lo tanto no es solo compañía, entretención o ruido de fondo, es un agente socializador que ocupa un lugar privilegiado en la sociabilidad adolescente y es clave para entender la conversación social. En este sentido, como lo han señalado diferentes autores (Sánchez Noriega, 1997; Montero, 2006; Cruzvillegas, 1998), sus mensajes son lugares de referencia obligados.

Generalmente se asume que los jóvenes y adolescentes son consumidores casi exclusivos de programas de televisión segmentados hacia esa franja etárea, sin embargo, en la encuesta del CNTV un $74.7 \%$ de los encuestados de todas edades dice ver noticieros todos los días y ello se confirmaría porque el consumo comienza a subir entre 19 hrs. alcanzando su peak entre 21 y 22 hrs., franja horaria en que los cuatro canales mas importantes de la televisión abierta dan noticias y en que los padres ya han regresado del trabajo y la familia tiende a reunirse. Según la encuesta del CNTV en 2008 los noticieros eran el programa de televisión abierta más visto en familia superando a las teleseries y películas, con un 74,4\% de evaluación de "buena" a "excelente”.

\footnotetext{
${ }^{1}$ Mientras baja el consumo diario de Televisión abierta en todos los grupos de edad de 79\% el 2005 a $76 \%$ el 2008, sube el de Internet de 15\% a 26\% (CNTV, 2008, p10).

${ }^{2}$ Consejo Nacional de Televisión (CNTV). Informe 13/17 Jóvenes Chilenos, 2005.

${ }^{3}$ En el grupo de edad de 16 a 25 años esta evaluación sube a 74.6\%, CNTV Sexta Encuesta Nacional de Televisión, 2008.
} 
Este artículo recoge algunos resultados de una investigación que buscaba establecer el consumo y uso que hacen adolescentes de Santiago de los noticiarios de televisión ${ }^{4}$ y determinar sus percepciones respecto a como se los representa en ellos. La investigación incluía la realización de grupos focales y entrevistas etnográficas a estudiantes hombres y mujeres entre 15 y 18 años. El artículo se basa en la información recogida en 18 entrevistas en profundidad de corte etnográfico realizadas a estudiantes hombres y mujeres, de tres colegios de Santiago ${ }^{5}$ a los cuales se les invitó a participar en un estudio sobre televisión, sin especificar que se hablaría sobre los noticiarios de modo de no sesgar la muestra. En la primera parte de las entrevistas se buscó establecer el contexto de consumo (horarios, lugares y modos de ver televisión) y en la segunda se recogió las percepciones sobre los contenidos entregados por la televisión, con especial énfasis en la información sobre adolescentes y jóvenes que aparecen en los noticiarios chilenos de televisión abierta, para posteriormente centrarse en los usos que se hace de esa información y los efectos que los noticieros tienen en sus vidas cotidianas.

El artículo profundiza en el contexto cotidiano en el cual se "consumen" los noticiarios así como en el uso social y percepciones de los discursos de información trasmitidos por los noticieros difundidos por la televisión chilena por parte de grupos de adolescentes.

\section{Etnografía del consumo}

La mayor parte de los entrevistados señalaron que en sus casas existían más de dos televisores, uno de los cuales mayoritariamente se encontraba en el living-comedor y el o los otros estaban en los dormitorios de los hijos/as y de los padres. De acuerdo a la información recogida la cantidad y ubicación de los aparatos de televisión juega un papel fundamental en los modos de sociabilidad diaria de las familias. En aquellas donde los padres e hijos se reúnen para comer o compartir y el televisor está en el living o comedor las posibilidades de ver en conjunto las noticias aumentan, a diferencia de los hogares en que los televisores están en los dormitorios y donde no existe la costumbre de juntarse a conversar al final del día.

Los adolescentes tienen clara conciencia de las implicancias de estos modos de consumo televisivo, lo que se resume en la siguiente frase: "Somos tan individualistas...

\footnotetext{
4 Se trata de la investigación FONDECYT 1070916 "Identificación y usos sociales de los discursos de información televisiva por parte de jóvenes del gran Santiago. Recepción y representación mediática de los jóvenes en el telediario".

${ }^{5}$ Los estudiantes pertenecían a un colegio particular de Las Condes, un municipal de Santiago Centro y un particular subvencionado de Nuñoa.
} 
por ejemplo en mi casa que cada uno tiene su televisor, cada uno se encierra en su mundo" (Entrevistado 3, LC) ${ }^{6}$.

A este individualismo además contribuyen los horarios de trabajo de los adultos que generalmente llegan cansados del trabajo a la casa y se retiran al dormitorio a ver televisión como un modo de desconectarse de los problemas diarios. Sin embargo, se constata una diferencia entre hombres y mujeres adolescentes, mientras los primeros tienden a compartir menos con los padres y a permanecer más en sus propios dormitorios y espacios, las mujeres - especialmente cuando no tienen clases al día siguiente ni los padres la obligación de levantarse temprano para ir al trabajo- tienden a ver televisión en el dormitorio de éstos.

En aquellos hogares donde los padres ven noticias, los hijos/as tienden a motivarse más con estas y verlas más que los otros adolescentes. Lo mismo ocurre cuando hay profesores, especialmente se menciona a los de las áreas humanistas y sociales, que ponen en la conversación de clases temas de actualidad, lo cual se transforma en un incentivo para el consumo de noticiarios por parte de los adolescentes.

Las rutinas diarias de los adolescentes están fuertemente marcadas por los horarios y espacios escolares y el consumo televisivo afincado en el hogar se produce en los momentos en que no se está en el colegio o liceo. Así, algunos de los adolescentes que cuentan con televisor en sus dormitorios dicen prenderlo en la mañana, a la hora de despertar y lo escuchan y miran de reojo mientras se visten. Al llegar del colegio prenden la pantalla mientras hacen otras cosas: hablan por teléfono, escuchan y bajan música, chatean en el computador, navegan por Internet o incluso hacen deberes u ordenan sus útiles del colegio.

Estas prácticas confirman lo detectado en el Informe 13/17 donde se caracterizaba metafóricamente el consumo de medios de los adolescentes y jóvenes como torta milhojas "son capaces de hacer un consumo de medios y sus respectivos contenidos como si fuera un trozo de torta milhojas, con todas sus capas y rellenos juntos, comidos y digeridos de una sola vez" (Informe 13/17.2005, p. 59). La simultaneidad del consumo de medios de comunicación, que puede asimilarse al zapping que se hace con el control remoto, permite a los adolescentes armar sus propias programaciones multimediales a partir de diferentes fuentes (cfr. del Villar et. al, 2008) variando el tipo de atención que se da en un momento determinado a alguna de ellas.

Los noticieros centrales de la televisión abierta, por horario, son la transición entre programas de entretenimiento bailes, música y concursos orientados a los más jóvenes, seguidos por teleseries y los programas nocturnos. A nivel familiar, suelen ser el momento en que toda la familia está en casa, aunque no necesariamente reunida. Los adolescentes

\footnotetext{
${ }^{6}$ Las citas de los entrevistados/as son identificados con un número y las iniciales de la comuna a la que pertenecen sus colegios.
} 
no ven los noticieros concentrados en ellos, miran de reojo la pantalla con el computador funcionando mientras chatean, entran y salen de los espacios, conversan con la familia, comen y/o hablan por teléfono. Actitud diferente a la de los adultos que pueden comer mientras ven las noticias y hablan sobre los temas que éstas van difundiendo, especialmente en los momentos en los cuales baja el interés por el tipo de información que se entrega: la secuencia de deportes y a veces la política en el caso de las mujeres.

Para los adolescentes los noticieros trasmitidos por la televisión abierta son parte del ruido ambiente hogareño nocturno, los perciben como programas destinados a los adultos de los cuales ellos pueden extraer algunos contenidos que les resultan útiles: ya sea en función de sus futuras opciones de estudio o de la conversación social. Sin embargo, ello no significa que no les interesen algunas noticias o estar informados, como se verá más adelante, o que la televisión no tenga ninguna importancia en la definición de temas que les preocupan.

\section{Percepciones sobre la televisión}

Los jóvenes perciben a la televisión como una fuente de entretención más que de información ${ }^{7}$, en este sentido sienten que su consumo no demanda ningún esfuerzo, que no requiere de una concentración exclusiva o atención sostenida. Por otra parte, y dado lo anterior, perciben que promueve una actitud pasiva frente a lo que se emite y facilita la dispersión por la gran cantidad de información que entrega.

Se percibe a la televisión básicamente como prodigadora de entretención, como aquello que ofrece la posibilidad de "escaparse de los problemas cotidianos", de "pasar el rato". Esta percepción sobre la televisión no está referida solo a los adolescentes y jóvenes, pues consideran que los adultos también buscan entretención fácil que no les demande mucha energía ni esfuerzo permitiendo una evasión fácil y rápida:

Trabajan tanto, que lo único que quieren al llegar a la casa es descansar. No sé si la gente ve la tele para informarse. Para mi la tele, es como un momento de relajarte y filo, ver un poco de tonteras. (Entrevistado 4, N)

Podría pensarse que al caracterizar a los programas de televisión como espacios de diversión fácil y poco exigente se la percibe como poco estructurada, con mucho de

\footnotetext{
${ }^{7}$ Este tipo de percepciones son coincidentes con lo señalado por Fuenzalida cuando sostiene que: "la etnografía de la recepción muestra que el Hogar para estudiantes y trabajadores que regresan a casa, así como para amas de casa en ciertos momentos de su ritmo diario, aparece como un espacio-tiempo psicológicocultural de descanso de las tareas vinculadas con la ley del rendimiento" (Fuenzalida, 2006, p50).
} 
improvisación. No obstante la percepción es exactamente la contraria. La televisión es vista como lo estructurado, con sus segmentaciones horarias según tipos de audiencias que se repiten día a día en el mismo orden, e incluso al interior de ciertos programas- los noticieros, por ejemplo- se percibe la reiteración diaria de cierto orden rutinario que se sigue en cada una de las emisiones. Aparece así la TV y los noticiarios como un espacio ritualizado, donde se sabe qué ocurrirá según la hora que sea, algo parecido a la percepción que se tiene de su mismo consumo.

De acuerdo a la visión de los adolescentes los noticieros de la televisión muestran el mundo en la superficie, donde se tocan muchos temas sin profundizar en ninguno, las notas e imágenes se repiten e incluso no se sabe si se dice, o no, la verdad. Esto les da la apariencia de espacio abigarrado, aunque con un orden interno preestablecido, donde se mezcla lo banal con el drama, el deporte con las guerras, la política con la farándula, donde los tiempos destinados a la cobertura de estos temas diversos es absolutamente arbitraria, lo que deja la sensación de manipulación.

El noticiario es percibido además como un espacio de adultos, destinado a los intereses de los adultos, desconociendo temas de actualidad que convocarían el interés de los jóvenes. Algunos de ellos piensan que no contribuyen a interesar y educar respecto a temas políticos en el sentido en que los jóvenes entienden la política, referida a los temas que preocupan actualmente a la humanidad: calentamiento global, maltrato a los animales, intolerancia cultural, entre otros.

Perciben que la política en los medios es entendida en el sentido de los partidos o conglomerados políticos de izquierda o derecha, tal como la entienden y entendieron los adultos y-además de la restricción del concepto- encuentran que se trata de algo antiguo, de otra época, que impide que afloren otros modos de concebir y hacer la política y con ello marginan a los jóvenes ${ }^{8}$. Esta manera anticuada y reduccionista de entender la política entre izquierdas y derechas, más cercana a los tiempos de la guerra fría que al siglo XXI, a los adolescentes les molesta y les hace sentir que en este quedarse en el pasado se les quita la oportunidad de vivir y actuar sobre el presente; el tiempo de los otros -de los adultos- se devora su presente.

Hablan de odios de hace mil años ... si está bien, pero hay que hablar de lo que pasa ahora, la cosa ecológica, la cosa económica, que es lo que afecta al mundo ahora. Me parece súper egoísta centrarse en problemas de hace 30 años y que ellos se van a morir y no van a haber solucionado los problemas de ahora. (Entrevistado por Acevedo y Pérez, 2008)

\footnotetext{
${ }^{8}$ Para profundizar en las percepciones que los jóvenes y adolescentes tiene sobre la política a partir de cómo la tratan los noticieros de televisión cfr. Acevedo y Pérez (2008).
} 
Los adolescentes perciben que temas políticos de actualidad que a ellos les interesan no son tocados, o solo lo son de manera parcial por los noticieros: por ejemplo, el tema medio ambiental, los movimientos sociales o la cultura alternativa, lo que fortalece su convicción de que los noticieros están hechos para los adultos. Ante ello lo que hacen es buscar la información requerida en otras fuentes como Internet o visitando lugares en los cuales pueden obtenerla.

En relación a los canales de televisión y la conexión entre líneas editoriales e intereses políticos, económicos y religiosos hay ciertos discursos hechos, los cuales tienden a tener poca densidad cuando se trata de profundizarlos, sin embargo, donde no hay muchas dudas es respecto a que los noticiarios obedecen a intereses específicos y ello se manifiesta en los modos de entregar las noticias. Así, la mayoría dice que TVN es del gobierno y por eso no critican los aspectos negativos de éste, que el Canal 13 es católico y por tanto no dan noticias sobre otras religiones o sobre temas que vayan contra lo que la Iglesia piensa; por ejemplo, se informa muy brevemente sobre la marcha gay, pero se le da muchos minutos a la marcha contra la píldora del día después, aunque esta última haya convocado a muy poca gente.

Respecto a Chilevisión hay dos posturas sobre la ingerencia y uso político que hace el candidato a la presidencia Sebastián Piñera del canal del que es dueño y los noticieros que éste emite. Para unos hay independencia del canal, para otros es parte de su campaña: "Muy dueño del canal será, pero yo creo que independiente de eso, el no ve todas las noticias que van pasando", afirma una entrevistada y otra opina: "El es de derecha y tampoco va a permitir que en su canal se muestren cosas que no lo benefician, y menos ahora que vienen las campañas presidenciales" (Entrevistada 6, SC).

Los adolescentes tienen una clara opinión respecto a que los medios de comunicación manipulan las noticias en función de la venta y en el caso de la televisión para obtener mayor rating. Distinguen distintos tipos de estrategias de manipulación y entre las razones de éstas diferencian entre aquellas de índole económica de las de naturaleza ideológica.

Las percepciones sobre la manipulación de las noticias son transversales, abarcan a hombres y mujeres y a los diversos tipos de colegios en que estudian los adolescentes entrevistados (particulares, municipalizados o particulares subvencionados). En relación a las estrategias utilizadas en los noticieros que demuestran esa manipulación, está el manejo de los tiempos que se da a cada noticia y su mayor o menor reiteración. Se percibe que se puede minimizar algo importante y por otra parte, darle mucho tiempo y reiterar una noticia banal hasta hacerla parecer como algo importante.

Encuentro medio ridículo que con cada noticia hagan una crónica. El ejemplo mas ridículo que he encontrado es una vez que en TVN hicieron un reportaje sobre en una calle en que habían muchos hoyos. Y le preguntaban a las personas y ellos decían "sí, en esta calle hay 
muchos hoyos", doce hoyos ponte, tú, sólo faltaba entrevistar los hoyos. Les falta ser más sintéticos. (Entrevistado 5, N)

Les molesta la repetición de ciertas noticias y el alargue de otras, y piensan que ello se hace para completar la hora de noticiario, para "matar el tiempo", pues aunque se entrega una variedad amplia de noticias, en muchas de ellas que se considera importantes se lo hace sin entregar un contexto ni los elementos que permitan comprenderla para que el televidente saque sus conclusiones

Perciben que las noticias destacan los aspectos más negativos de lo que ocurre en el país y el mundo y que se mueven entre lo negativo y el drama morboso. Entienden esto como otra estrategia de manipulación que se explica por razones económicas: para vender, buscando capturar audiencias.

Otras de las razones que explicarían la manipulación de los noticieros son ideológicas. Estas razones ideológicas abarcan dos espectros, por una parte el adormecimiento de conciencias - "para que la gente se sienta menos mal con su vida"- y por otra, para inducir determinados comportamientos. En este último sentido algunas noticias, tratadas de una manera específica, cumplirían una función de corte normativo en relación a la familia y la ética familiar -"para obligar a las familias a proteger a los hijos o culparlas si nos los han protegido"-.

Esta razón de que los canales supervisan el orden familiar a través de las noticias que difunden y del morbo con que las entregan, dejando siempre una moraleja, refuerza la idea de que los noticiarios están dirigidos a un público adulto, donde no se considera los intereses informativos de los jóvenes, pero sí se los utiliza como fuentes noticiosas, aunque entregando imágenes estereotipadas y distorsionadas de ellos. La sexualidad, las manifestaciones contraculturales y las movilizaciones callejeras son los temas que atraviesan la agenda mediática para referirse a los adolescentes y jóvenes. Ellos así lo perciben al referirse a las noticias que más impacto han provocado y en las cuales sienten

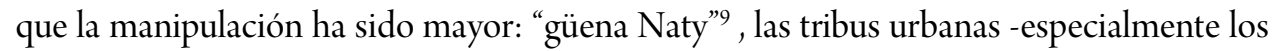
pokemones- $\mathrm{y}$ las movilizaciones de los pingüinos ${ }^{10}$ aparecen como aquellas donde los estereotipos estigmatizantes sobre la sexualidad y la protesta estudiantil fueron mayormente manipulados. Ello se hace especialmente evidente a partir de los modos en que son representados dos tipos de jóvenes cuyas motivaciones y maneras de ser son absolutamente diferentes, pero cuyas imágenes -en ambos casos- son igualmente negativas por el tipo de tratamiento que se hace de las noticias.

\footnotetext{
9 "Güena Naty" hace referencia a la noticia que daba cuenta de manera escandalosa de una práctica de sexo oral entre adolescentes que fue puesta en Internet. Naty es el nombre de la muchacha involucrada.

${ }^{10}$ Las movilizaciones de los pingüinos se refieren a las marchas callejeras de los estudiantes secundarios protestando contra la ley de educación.
} 


\section{Tribus ${ }^{11}$ y pingüinos. Representaciones mediáticas de jóvenes y adolescentes}

Ante la pregunta “¿Como se muestra a los jóvenes en los noticiarios?”, las respuestas coinciden en que los medios entregan imágenes negativas de los jóvenes, asociándolos a la violencia, la anomia y presentándolos dentro de un todo indiferenciado, cayendo en un esencialismo que los perjudica: "La perdición, la juventud perdida, los pokemones, las tribus urbanas y la generalización al mil por ciento” (Entrevistado 1, SC).

Respecto a las tribus, las percepciones son claras y contundentes al afirmar que lo que se muestra de ellas es lo negativo, ya sea por su modo de expresar públicamente su sexualidad y vestirse y actuar de manera transgresora a los mandatos establecidos de género, como es el caso de pokemones y emos, o bien por sus expresiones violentas y su relación conflictiva con otros grupos como ocurre con nazis, neonazis y punkies.

Las tribus urbanas, siendo un fenómeno de gran visibilidad dada la colonización de ciertas zonas de la ciudad que han hecho estos grupos y la difusión de su existencia en los medios de comunicación, no abarcan al conjunto, ni a grupos numéricamente importantes de los adolescentes y jóvenes. Más bien son expresiones de grupos minoritarios, pero con alta exposición pública, dado que se reúnen en las calles y plazas para desplegar allí su sociabilidad. Sin embargo, en la televisión, en los noticieros y también en los programas franjeados para adolescentes y jóvenes la tendencia es hacer aparecer a algunos de estos grupos como representativos de la juventud, lo cual genera molestia entre los que no se identifican con esta tendencia. Molestia que se resume en la siguiente frase: "muestran una cara, la cara mas ahueonada de los jóvenes. Los pokemones, gente que es aporte cero para el país” (Entrevitado 6, LC).

Los pokemones han sido en los últimos años el grupo al que mayor importancia han dado los medios de comunicación, resaltando sus vestimentas, maquillaje y peinados, pero especialmente mostrando su rupturismo en temas de sexualidad, ya sea por su manifiesta ambigüedad sexual y desenfado en las manifestaciones públicas de ésta, su lenguaje particular donde la palabra "ponceo" es la que más se ha destacado.

Últimamente no se puede hacer nada porque enseguida te encasillan en una tribu, que perteneces a un grupo .... Se muestra todo lo malo y no ven como nada bueno en ello, específicamente en lo que son los pokemones, los emos, los picachos ...

\footnotetext{
${ }^{11}$ Se usa el término tribu no en el sentido antropológico del término, sino recogiendo el concepto usado vulgarmente en los medios de comunicación para designar a grupos de jóvenes cuyo consumo cultural, vestimenta, ideología y modos de actuar los particularizan.
} 
Todos muestran solo lo malo, que salen, que toman en las plazas, como se visten ... que no sé que mató a otro joven, que le pegaron un botellazo ... de cierta manera las noticias dicen "Ah este grupo es malo, porque como mató a este joven... No es la persona como particular, no es Juanito Pérez que mató a este niño y le pegó en el suelo, sino que estos pokemones mataron al niño, al tiro encasillan a todo el grupo" (....) los pokemones, los pelolais ... a mi me cargan esas noticias, no me siento parte de esa noticias. (Entrevistada 2 $\mathrm{SC})$

Hay conciencia en que la televisión al mostrar lo negativo de algunos estigmatiza al conjunto y ello exacerba la discriminación y desconfianza hacia grupos de jóvenes, especialmente los flaytes, pokemones, punkies y neonazis.

Igual yo me visto de negro y todo eso, como que ya se me ha clasificado en uno de los grupos satánicos y cosas así, lo mismo que los flaytes, como que ya los tienen identificados ¡ah los gueones flaytes! $Y$ te pueden robar... ... yo encuentro que la misma sociedad en vez de ayudarnos, ella mismo nos va apartando. Si se supone que nosotros vamos a ser el futuro de ellos mismos, no nos tiene porque rechazar de esa forma, es como que te aparcelan, te clasifican y te echan, te dejan en un rincón porque tenís una onda diferente, tenís un pensamiento diferente. (Entrevistado 1,SC)

Respecto a la estigmatización de ciertas tribus por los MCM se ven posturas opuestas, algunos tienen conciencia de la manipulación y el efecto de fragmentación que ello tiene a nivel de la juventud, pero otros se hacen parte del prejuicio y asumen que esas tribus no aportan nada positivo, dejan una mala imagen de los jóvenes como conjunto:

Al final es como "pitéate un pokemon", eso es lo que sacamos en limpio. Da tanta rabia, porque invaden nuestro terreno. Estamos siendo todos agrupados por culpa de ellos. Dan una mala cara de Chile. No aportan en nada. (Entrevistada en Acevedo y Pérez)

Otros ven en las tribus una forma de manifestar su malestar y sus diferencias con los adultos, asumiendo que los integrantes de las tribus no son tan distintos a los estudiantes que protestan en las calles, pues ambos grupos interpelan al sistema e instalan discursos y actitudes que manifiestan su malestar social y cultural.

Lo mismo que pasó con las marchas pingüinas y todo eso fue lo que me gustó, onda la misma juventud, como que onda aparte de toda la onda y todo eso, los flaytes los emos y todo eso, como que igual somos uno: somos la juventud; igual les torcimos casi la mano a los adultos, que igual nos están manipulando en cierta forma. (Entrevistado 1, SC) 
Si respecto a las tribus y como son representadas en los noticiarios de televisión hay posturas diferentes -a favor y en contra- donde sí existe consenso en todos los adolescentes entrevistados es respecto a la manipulación ejercida por los canales cuando se ha informado sobre las manifestaciones estudiantiles.

El otro grupo juvenil que tiene una cobertura amplia en los noticiarios son los estudiantes movilizados en las calles, se percibe que las manifestaciones estudiantiles son distorsionadas en la información de la televisión a partir de estrategias de manipulación que buscan mostrar cómo algunos encapuchados y algunos jóvenes realizan actos violentos, y no muestran a la mayoría que se manifiesta de manera pacífica. Nuevamente se ejemplifica que otro modo de manipulación es la descontextualización, lo que opera a través de entrevistar y mostrar a los jóvenes mas despistados, que no saben por qué están protestando en las calles, en lugar de mostrar a los lideres que argumentan y ponen en contexto la protesta. Esta percepción es tanto de hombres como de mujeres y atraviesa clases sociales y tipo de colegios de pertenencia.

Una vez más se reitera que ante la falta de información por los canales que se supone la entregan, se busca otras fuentes para estar informados respecto a lo que les interesa, ya sea en las asambleas estudiantiles, los boletines y panfletos y las convocatorias y mensajes a través de blogs y los teléfonos celulares. Los jóvenes y adolescentes usan la batería tecnológica comunicacional completa cuando les interesa algo.

\section{Efectos y usos de los noticiarios}

Los jóvenes perciben que los mensajes emitidos en los noticiarios de televisión tienen efectos directos sobre sus vidas, pues los adultos asumen que las representaciones que se hacen sobre los jóvenes son parte de la realidad en que viven sus hijos, por lo cual en función de protegerlos les niegan permisos para ir a fiestas, ya que allí se drogan, se emborrachan y se "poncea". Aquí es cuando se percibe el papel de custodio de los valores de los adultos, de una normatividad conservadora que juegan los noticiarios de televisión, apelando a la atención de los padres, y cuyos efectos son la vigilancia, la represión o la sobreprotección sobre los jóvenes y adolescentes. "Niña no quiero que hagas esto o esto, porque te puede pasar algo" (Entrevistada 3, N).

En otros casos los adultos utilizan la información que sale en los noticiarios para prevenir a los jóvenes y aconsejarlos sobre temas de sexualidad (el caso más recurrente fue el Güena Naty) o sobre consumo de drogas, abriendo temas de conversación que son generalmente tabú. Así, la información aparecida en los noticiarios funciona como ventana para permitir la apertura de ciertos tópicos que de otro modo los padres y profesores no sabrían cómo abordar con los hijos y alumnos/as. 
La tendencia a esencializar y a pensar que todos los jóvenes son iguales -que se deriva de la construcción de ciertos estereotipos sobre adolescentes y jóvenes- y la estigmatización que se hace de ellos, se perciben como algo que afecta al conjunto, y esto se manifiesta en la creación de prejuicios hacia los jóvenes

Por culpa de un joven que hizo algo, entonces es culpa de todos los jóvenes... Claro, como que te miran y dicen "ah, el joven", como despectivamente. En el fondo con las noticias, las personas se quedan con lo que sale ahí. (Entrevistada 1, SC)

Los adultos ven cómo actúan ellos y nos meten a todos en el mismo saco. Como que vamos a hacer lo que ellos hacen. Como que los jóvenes somos destrucción, como que pasamos y dejamos la cagá. Lo veo en mis hermanos grandes, muchos profes también. (Entrevistado 2,N)

Pese a que la mayor parte de los entrevistados/as asume como negativo para sus vidas cotidianas el modo en que se informa sobre los jóvenes y la sobreprotección y restricciones a las que los someten sus padres, motivados por lo que ven en la televisión, otros adolescentes inconcientemente internalizan el prejuicio, como lo refleja la siguiente conclusión de uno de ellos: "Siempre la sobreprotección es mala, pero tampoco hay que darle tanta libertad, porque si no se va a volver ... lo más probable que termine en la cárcel” (Entrevistado 5, SC).

Los adolescentes no están ajenos a las noticias. Su percepción negativa de la manera en que es entregada la información por los noticiarios de televisión abierta no los llevan a renegar de su importancia, más bien buscan nutrirse de otras fuentes, especialmente Internet, donde portales como Terra o Emol son visitados frecuentemente a la búsqueda de noticias o información que les interese.

Los adolescentes ven noticias de manera selectiva. Ponen atención a aquellas cosas que se vinculan con sus intereses profesionales futuros: temas legales, de policía, fiscales y crímenes si se quiere estudiar derecho; temas deportivos, si se quiere estudiar educación física, temas de actualidad en general si se quiere estudiar periodismo. Las noticias internacionales y de economía no les son lejanas y reconocen que les interesan en la medida que pueden repercutir en sus vidas.

Algunas entrevistadas dicen ver temas de política en los noticieros porque ello les permite conversar, contradecir y discutir con sus padres sobre esos tópicos. Otro de los argumentos por los cuales se dice que estar al día con lo emitido por los noticieros tiene un uso y valor, es para tener tema de conversación sintiéndose parte de una cierta comunidad comunicativa y tener la posibilidad de sostener una conversación sin quedar al margen o sentirse ignorante. Lo cual confirmaría el rol que cumplen los noticieros en la sociabilidad de adolescentes y jóvenes pauteando los temas de la conversación social. 
Otro de los usos de los noticieros de televisión por parte de los jóvenes surge de la demanda del colegio, aunque es de destacar que la mayoría de ellos señala que son muy pocos los profesores que incluyen temas de actualidad en su conversación en clases. Sin embargo, se valora cuando los profesores ponen temas de actualidad a la discusión del curso, ya que ello les permite desarrollar sus puntos de vista y demostrar que están bien informados.

\section{Comentarios finales}

Para los adolescentes entrevistados, la televisión ocupa un espacio importante de sus tiempos cotidianos, sin embargo, la atención que se le presta es secundaria, pero no por ello intrascendente. En este sentido, la televisión sigue operando con agente de socialización ${ }^{12}$.

Los adolescentes están interesados en las noticias, aunque no necesariamente en la forma en que son difundidas por los noticieros de televisión. Tienen una visión crítica del modo en el cual se presentan los temas, estimando que se prioriza lo impactante sobre lo importante, lo banal sobre lo trascendente, lo cual se evidencia, por ejemplo, en el tipo de tratamiento dado a la información y el tiempo destinado a entregarla.

Frente a la desconfianza respecto a la calidad y densidad de la información entregada por los noticieros de la televisión abierta, en los temas que les preocupan ellos se dedican a buscarla en otras fuentes. "Lo que me interesa no lo saco de la tele", es la frase que resume esa actitud. Internet aparece como una de las fuentes a las que más se recurre para profundizar en el conocimiento de algo que les interesa; lo cual implica una actitud activa. Los adolescentes como constructores de la información que requieren, autogestionan la búsqueda de la noticia (saltando de página en página, usando buscadores como Google, accediendo a Youtube, buscando en Wikipedia o en blogs. Muchas veces el interés por indagar más surge de lo escuchado en los noticiarios de televisión, pero como sienten que la información que se les entregó es poca, se dedican a buscarla por esta vía.

Los adolescentes pueden ser definidos más como especialistas que como generalistas en lo referido a las noticias. Buscan solo lo que les interesa, lo demás lo descartan. Leen el diario en Internet, varios mencionan Emol y dicen no leer el diario en papel más allá de los titulares. Terra es un portal donde muchos ven noticias al abrir páginas de Messenger.

\footnotetext{
${ }^{12} \mathrm{Al}$ hacer referencia al rol socializador de la televisión resulta ineludible el tema de los efectos de los mensajes sobre los telespectadores. Más aún, cuando se trata de adolescentes, cuyas identidades están en proceso de definición. Los dos puntos de vista polares que han planteado los estudiosos de los efectos de los mensajes sobre las audiencias ha sido asumirlos como sujetos pasivos o activos, ideológicamente dominados o resistentes ( Cfr. Curran, 1998; Morly, 1998; Carlón, 2005).
} 
Esto corrobora lo afirmado por Neuman (2002) cuando sostiene que "pareciera que las audiencias han desarrollado una considerable habilidad para organizar, filtrar la información a partir de estrategias de atención parcial. La mayoría de las personas no se siente bombardeada o sobrecargada por una expansión de los medios masivos. Por el contrario, la mayoría busca más medios y responde entusiastamente a la ampliación de las alternativas" (Neuman, 2002, pp. 223-224).

Los jóvenes tienen opinión respecto a la televisión y conciencia de la manipulación de las noticias, una forma de resistencia a ello es utilizar el zapping no como un mecanismo de evasión o de organizar su propia programación, sino de formarse una opinión sobre un acontecimiento a partir de la cobertura que de este hacen diferentes canales. En este sentido, los resultados coinciden con otros hallazgos sobre atención selectiva, percepción y retención (Hovland; Festinger, en Neuman, 2002) y permiten discrepar de lo planteado por Rincón cuando señala que "Por la precaria información que se recibe, los ciudadanos se han convertido en una sociedad conformista que viene aceptando el sino trágico como parte de su destino, los televidentes han sido excluidos de la realidad. Solo les han dejado como posibilidad de acción la pasividad y el entretenimiento" (Rincón, 2002, p51). En el caso de los adolescentes entrevistados se detecta una clara conciencia sobre los juegos de poder y manipulación que se hace en los informativos.

Donde más se detecta esa manipulación es en lo referente a la información que entregan los noticiarios que les atañe más cercanamente a los jóvenes: temas vinculados a la sexualidad (sexo en espacios públicos, píldora del día después), manifestaciones contraculturales (marcha del orgullo gay, reuniones callejeras de grupos de pokemones) y movilizaciones políticas de los estudiantes ("marchas pinguinas").

La percepción de los adolescentes, recogida en las entrevistas respecto a los noticiarios, es que éstos parecen servir más para informar al mundo adulto sobre los jóvenes que para instaurar la mirada y temática juvenil en la sociedad. Para los adultos los noticieros son "la ventana al mundo" y el principal canal de información sobre lo que sucede en su entorno, incluyendo las tendencias sociales en las que se insertan sus hijos, son además la bisagra que les permite la apertura de conversaciones sobre temas tabú como la sexualidad y las drogas. En este sentido, se provoca el fenómeno inverso al planteado por Meyrowitz cuando sostiene "lo que hay de verdaderamente revolucionario en la televisión es que ella permite a los más jóvenes estar presentes en las interacciones de los adultos" (Meyrowitz en Martín-Barbero, 2000).

Al mostrar lo negativo de los jóvenes se les afecta en su cotidiano pues los padres y profesores tienden a definir conductas, a hacer discursos y tratar de controlar y reprimir cualquier manifestación de sus hijos o alumnos que se aproxime a lo trasmitido en los noticiarios. 


\section{Referencias bibliográficas}

Acevedo, Jorge y Juan Carlos Pérez. (2008). Jóvenes, telediarios e identidad política. Estudio de recepción de los noticieros centrales de la televisión abierta en el Gran santiago. Tesis de Magíster en Comunicación Política. Dir. B. Amigo, Universidad de Chile.

Carlón, Mario. (2005). Los sujetos telespectadores: son activos o pasivos. En Diálogos de la Comunicación, Na 71-2005, Colombia, pp. 18-27.

Consejo Nacional de Televisión. (2008). VI encuesta Nacional TV, Chile en http://www.cntv.cl/link.cgi/Estudios/

CNTV y Mac Cann Ericsson. (2005). Informe 13/17 jóvenes chilenos, en www.cntv.cl/link.cgi/Publicaciones/885 